\title{
PNAIC: ALGUMAS REFLEXÕES A PARTIR DE UM ESTUDO DE REVISÃO BIBLIOGRÁFICA
}

\author{
Sandra Pottmeier ${ }^{1}$ \\ Lais Oliva Donida ${ }^{2}$ \\ Marta Helena Cúrio de Caetano ${ }^{3}$
}

\begin{abstract}
Resumo
Este trabalho objetiva analisar produções acadêmicas publicadas entre 2013 e 2017 sobre o Pacto Nacional pela Alfabetização na Idade Certa - PNAIC. A partir de uma revisão bibliográfica realizada nas bases de dados: Repositório da UFSC, CAPES, Scielo e Redalyc, 14 trabalhos foram selecionados. A discussão revelada, a partir de análise de dados, evidencia que os cadernos de estudo do PNAIC vêm contemplando os usos sociais de leitura, escrita, oralidade e análise linguística. Considera-se, contudo, que ainda há necessidade de um aprofundamento quanto às concepções de leitura, assim como na caracterização do leitor pautadas em uma fundamentação teórico-metodológica consistente, em função da presença de diferentes compreensões teóricas que são apresentadas, muitas vezes, de modo superficial e, até mesmo, conflitivos entre si nos cadernos do PNAIC.
\end{abstract}

Palavras-chave: Linguagem. Formação. PNAIC.

\section{PNAIC: SOME REFLECTIONS FROM A BIBLIOGRAPHIC REVIEW STUDY}

\begin{abstract}
This work aims to analyze academic productions between 2013 and 2017 about the National Pact for Literacy in the Right Age - PNAIC. From a bibliographic review carried out in the databases: UFSC Repository, CAPES, Scielo, and Redalyc, 14 works were selected. The discussion revealed by the data shows that the PNAIC notebooks have been contemplating the social uses of reading, writing, speaking, and linguistic analysis. However, it is considered that there is still a need for a deeper understanding of the conceptions of reading, as well as the characterization of the reader based on a consistent theoretical-methodological foundation, due to the presence of different theoretical understandings that are often presented in different ways. superficial and even conflicting way in the PNAIC notebooks.
\end{abstract}

Keywords: Language. Formation. PNAIC.

\section{INTRODUÇÃO}

\footnotetext{
${ }^{1}$ Universidade Federal de Santa Catarina (UFSC) - Florianópolis - Santa Catarina - Brasil. Mestre em Educação pela Fundação Universidade Regional de Blumenau (FURB). Doutoranda do Programa de Pós-Graduação em Linguística da Universidade Federal de Santa Catarina (UFSC). Docente concursada na SED/SC, lotada na Escola de Educação Básica Padre José Maurício, município de Blumenau/SC. ORCID: http://orcid.org/00000001-7328-8656. E-mail: pottmeyer@gmail.com.

${ }^{2}$ Universidade Federal de Santa Catarina (UFSC) - Florianópolis - Santa Catarina - Brasil. Fonoaudióloga, mestra e doutoranda do Programa de Pós-Graduação em Linguística da Universidade Federal de Santa Catarina (UFSC). ORCID: http://orcid.org/0000-0003-3508-7030. E-mail: lais.donida@gmail.com.

${ }^{3}$ Fundação Universidade Regional de Blumenau (FURB) - Blumenau - Santa Catarina - Brasil. Mestra em Teoria Literária pelo Centro Universitário Campos de Andrade. Doutoranda pelo Programa de Pós-Graduação em Educação da Fundação Universidade Regional de Blumenau (FURB). Docente na rede particular de ensino de Blumenau, no curso de graduação em Letras e no Laboratório de Línguas da Fundação Universidade Regional de Blumenau (FURB). ORCID: http://orcid.org/0000-0002-9725-9806. E-mail: mhelenacc@gmail.com.
} 


\section{Linguagens - Revista de Letras, Artes e Comunicação - ISSN 1981-9943 \\ Blumenau, v. 13, n. 2, p. 301-319, maio/ago. 2019 \\ DOI: http://dx.doi.org/10.7867/1981-9943.2019v13n2p301-319}

O cenário educacional brasileiro tem se transformado nas duas últimas décadas no tocante à redução do analfabetismo no país. A partir dos anos 2000, investimentos em Políticas Públicas foram realizados por parte do Governo Federal, os quais se voltaram principalmente para a Educação Básica. Dentre as investidas da esfera federal, estão os programas de formação continuada para professores que atuam neste nível de ensino, principalmente para aqueles inscritos na área da Matemática e da Língua Portuguesa, tais como: Programa Gestão da Aprendizagem Escolar - GESTAR I (BRASIL, 2004) e GESTAR II (BRASIL, 2006), que atuam com o público dos anos finais do Ensino Fundamental (do $6^{\circ}$ ano ao $9^{\circ}$ ano); Mobilização pela Qualidade da Educação - PRÓ-LETRAMENTO (BRASIL, 2008), para professores dos anos iniciais do Ensino Fundamental (do primeiro ao quinto ano) e; mais recentemente, o Pacto Nacional pela Alfabetização na Idade Certa - PNAIC (BRASIL, 2012b; 2013; 2014; 2015), direcionado para professores alfabetizadores que atuam com crianças matriculadas do $1^{\mathrm{o}}$ ao $3^{\circ}$ ano do Ensino Fundamental.

Os dados apontados pelo Indicador de Alfabetismo Funcional - INAF (2018) evidenciam uma redução do analfabetismo no Brasil, com $8 \%$ de analfabetos. Em contrapartida, apenas $12 \%$ dos brasileiros na faixa etária entre 15 e 64 anos possuem nível de alfabetismo proficiente. O que implica pensar que há lacunas de ensino e aprendizagem que ainda não têm contemplado níveis satisfatórios no tocante aos usos sociais da leitura, escrita e numeramento em diferentes esferas sociais da atividade humana.

O PNAIC foi instituído pela Portaria $n^{\circ} 867$, de 4 de julho de 2012 com o intuito de criar estratégias a fim de promover a alfabetização de todas as crianças até o final do $3^{\circ}$ ano do Ensino Fundamental (BRASIL, 2012a). Isso, pois dados do Ministério da Educação MEC - vinham apontando índices insatisfatórios de crianças que ainda não estavam alfabetizadas até os oito anos de idade nas cinco regiões do país, em que Norte e Nordeste apresentavam números mais expressivos, $27,3 \%$ e 25,4\% respectivamente, seguidos de $9 \%$ na região Centro-Oeste, 7,8\% no Sudeste e 6,6\% no Sul (NASCIMENTO; HERNANDES; SANTOS, 2015).

O PNAIC surge, assim, como um compromisso formal entre os governos federal, estadual e municipal, com o propósito de assegurar a alfabetização de crianças de até os oitos anos de idade, de acordo com o previsto no Plano de Metas Compromisso Todos pela Educação (UNESCO, 2006). Em 2013, o PNAIC revela como prioridade o ensino e a aprendizagem da Língua Portuguesa no ciclo de alfabetização (ZANCHETTA JÚNIOR, 2017).

Para Alferes e Mainardes (2019, p. 48, grifos nossos), o PNAIC 
[...] é um programa abrangente, necessário e relevante para a melhoria da qualidade da aprendizagem no ciclo de alfabetização. No entanto, constitui condição necessária, mas não suficiente para promover uma alteração significativa dessa qualidade, pois enfatiza a formação continuada e a disseminação de determinadas concepções e práticas, por meio de materiais específicos. Uma alteração mais significativa demanda investimentos em outros aspectos, tanto intra quanto extraescolares.

Assim, questiona-se: $O$ que trabalhos acadêmicos têm compreendido acerca da alfabetização e letramento a partir do que tem sido apresentado nos cadernos do PNAIC? Qual é a compreensão de língua(gem) assumida nesse material direcionado para professores alfabetizadores e como os estudos têm utilizado essas diretrizes norteadoras do trabalho em sala de aula acerca dessa temática? A partir disso, o presente trabalho objetiva analisar produções acadêmicas entre 2013 e 2017 acerca do Pacto Nacional pela Alfabetização na Idade Certa - PNAIC.

\section{DISCUSSÕES TEÓRICAS}

A partir da década de 1980, o termo letramento começa a fazer parte de discussões e dos documentos oficiais (BRASIL, 1997; 2004; 2006; 2008) assim, como está presente nos cadernos do PNAIC (BRASIL, 2012b; 2013; 2014; 2015). Mesmo com os estudos do letramento na década de 1980, a concepção de língua(gem) mantinha raízes na alfabetização, nas normas gramaticais e não nas práticas sociais de leitura e escrita dos alunos que chegavam às escolas públicas. Vislumbrando à democratização do ensino e as dificuldades para ler e escrever de alunos advindos de diferentes contextos sociais, econômicos, culturais e geográficos, passou-se a pensar a leitura e o leitor partindo da realidade e das vivências desses sujeitos, portanto, considerando o que estes já sabiam, já haviam aprendido sobre leitura e escrita fora da escola.

Então, aos poucos as discussões da década de 1990 implicaram a elaboração e publicação dos Parâmetros Nacionais Curriculares - PCN para a disciplina de Língua Portuguesa entre outras áreas do conhecimento com vistas aos direitos de aprendizagem com enfoque na interação desses sujeitos de/na aprendizagem (BRASIL, PCN, 1997) retomado tal propósito mais adiante na Base Nacional Comum Curricular - BNCC (BRASIL, 2017). Os PCN (BRASIL, 1997) emergem assim, de discussões tanto no campo da Educação quanto no campo da Linguística, pois a partir desse documento, depreendeu-se um rompimento do estruturalismo e cognitivismo quanto ao ensino da leitura e da escrita nos processos de ensino 


\section{Linguagens - Revista de Letras, Artes e Comunicação - ISSN 1981-9943 \\ Blumenau, v. 13, n. 2, p. 301-319, maio/ago. 2019 \\ DOI: http://dx.doi.org/10.7867/1981-9943.2019v13n2p301-319}

e aprendizagem da Língua Portuguesa na Educação Básica. Tal modelo de ensino tradicional com ênfase aos estudos gramaticais no trabalho com o texto na sala de aula, destacava-se quanto:

- a desconsideração da realidade e dos interesses dos alunos;

- a excessiva escolarização das atividades de leitura e de produção de texto;

- o uso do texto como expediente para ensinar valores morais e como pretexto para o tratamento de aspectos gramaticais;

- a excessiva valorização da gramática normativa e a insistência nas regras de exceção, com o conseqüente preconceito contra as formas de oralidade e as variedades não-padrão;

- o ensino descontextualizado da metalinguagem, normalmente associado a exercícios mecânicos de identificação de fragmentos lingüísticos em frases soltas;

- a apresentação de uma teoria gramatical inconsistente uma espécie de gramática tradicional mitigada e facilitada (BRASIL, PCN, 1997, p. 18).

Nesse caso, a leitura e a escrita deixavam de ser compreendidas a partir do uso exclusivo das regras gramaticais e passavam a ser concebidas como práticas sociais na/pela relação de aprender com e pelo outro. Contudo, cabe dizer, que os PCN (BRASIL, 1997) apresentam a decodificação como um dos conceitos iniciais de leitura. Trata-se de apenas um dos procedimentos utilizado pelo sujeito quando este lê. A leitura envolve, assim, outras estratégias, conforme apresentam os PCN (BRASIL, 1997), dentre elas: a seleção das informações e dos textos, as inferências realizadas no ato da leitura a partir do conhecimento de mundo do leitor e da identificação e verificação da diversidade linguística de diferentes grupos sociais entre outros.

Entende-se a partir deste percurso, que se exige do professor de Língua Portuguesa uma posição teórica e metodológica, portanto, ter clareza de quais são suas intenções pedagógicas quanto aos processos de ensino e aprendizagem da leitura na esfera escolar. Para tanto, Geraldi (2013[1991], p. 4) orienta no tocante ao estudo da língua(gem) em que "em cada ponto, em cada nó, é uma resposta marcada pela eleição de postos de observação possíveis que somente uma sociologia do conhecimento e uma história do conhecimento poderão explicar". Ainda reforça o autor que "[n]ossos roteiros de viagens dirão de nós o que fomos: de qualquer forma estamos sempre definindo rotas - os focos de nossa compreensão" (GERALDI, 2013[1991], p. 4).

Como mencionam Leal e Souza (BRASIL, PNAIC, 2015c, p. 34):

Nesse debate, uma questão importante que se coloca é a seleção dos textos que o professor traz para a sala de aula e os que escolhe deixar fora, principalmente por considerar que são inadequados. Partindo do pressuposto de que os autores são situados em contextos que condicionam o que escrevem, para que escrevem e com 


\section{Linguagens - Revista de Letras, Artes e Comunicação - ISSN 1981-9943 \\ Blumenau, v. 13, n. 2, p. 301-319, maio/ago. 2019 \\ DOI: http://dx.doi.org/10.7867/1981-9943.2019v13n2p301-319}

quem estabelecem diálogos, defendemos que os textos precisam ser lidos com um olhar voltado para a circunstância de sua produção.

Nessa linha, reforça-se a importância de se partir dos textos que fazem parte da realidade dos alunos que chegam até essas salas de aula e, que esses possam de fato se apropriar além da escrita, das compreensões acerca das discussões produzidas na sala de aula na e pela mediação do professor. A produção de sentidos, neste caso, só é possível quando se leva em conta o discurso desse aluno, de que lugar ele fala e para quem ele se dirige. Portanto, o texto, nas palavras de Geraldi (2013[1991]) não pode ser trabalhado como pretexto para o ensino da gramática, para decodificação. Assim, como apontam Leal e Souza (BRASIL, PNAIC, 2015, p. 41) "Outro problema no trato com os aspectos linguísticos é que alguns professores concebem que estão trabalhando tal dimensão do ensino quando usam o texto para teorização gramatical."

Portanto, desde o período do processo de redemocratização da educação brasileira (1980), depreende-se a partir de Geraldi (2013[1991]), a importância do trabalho com os gêneros na sala de aula partindo dos textos lidos e escritos pelos alunos em outras esferas da atividade humana. O que já discutiu esse autor pensando na análise linguística é retomado nos PCN (BRASIL, 1997) sem citá-lo. Este documento ressalta que o "domínio da língua tem estreita relação com a possibilidade de plena participação social, pois é por meio dela que o homem se comunica, tem acesso à informação, expressa e defende pontos de vista, partilha ou constrói visões de mundo, produz conhecimento" (BRASIL, PCN, 1997, p. 23).

Segundo Rojo (2004, p. 3), a leitura como decodificação é um elo importante quanto ao acesso da leitura, contudo, essa prática não esgota "as capacidades envolvidas no ato de ler", a da compreensão leitora. Esta é cunhada pela "recuperação do contexto de produção do texto" para que haja assim, o diálogo entre o leitor e o texto; "definição das finalidades e metas da prática leitora", para quê?, por quê? -, para informar-se, para estudar entre outros objetivos; "percepção de relações de intertextualidade" a partir do diálogo com outros textos já conhecidos pelo leitor e que estão entrelaçados ao texto inicial; "percepção de relações de interdiscursividade" a partir da interação verbal com outros discursos já conhecidos pelo leitor; "percepção de outras linguagens" que possibilitam constituir e produzir outros sentidos ao texto pelo leitor; “elaboração de apreciações estéticas e/ou afetivas”, as quais apresentam as reações do leitor no ato da leitura, se este gosta ou não gosta da leitura que está realizando; “elaboração de apreciações relativas a valores éticos e/ou políticos" que implicam nas escolhas e posições ideológicas do leitor diante do texto, se concorda, se discorda do autor do texto (ROJO, 2004, p. 6-7). 


\section{Linguagens - Revista de Letras, Artes e Comunicação - ISSN 1981-9943 \\ Blumenau, v. 13, n. 2, p. 301-319, maio/ago. 2019 \\ DOI: http://dx.doi.org/10.7867/1981-9943.2019v13n2p301-319}

Tal qual como já criticava Kleiman (1989) que para constituir-se leitor, o aluno precisava aprender as técnicas, as estratégias de leitura em um ato mecânico, útil, sem tomarse conta de interpretar, compreender e fazer inferências acerca do que leu e do que lhe foi dado para leitura. Sem, portanto, que este aluno, pudesse escolher as suas leituras e sem que fosse "feito pelo processo de ensaio-e-erro", como destaca Silva (1995, p. 25).

Apesar de haver discussões na teoria sobre mudanças de paradigmas em programas de formação para professores e no preconizam os cadernos de estudos desses cursos, observa-se que tais propostas de ensino direcionadas para o alfabetizar letrando, pontualmente, no PNAIC, ainda acaba delimitando e determinando a idade certa para a alfabetização das crianças, até o $3^{\circ}$ ano do Ensino Fundamental. Bernardino (2013, p. 37) considera que "com exceção do PNAIC [que ainda estava em curso], os outros programas ainda deixaram lacunas na formação dos professores, que ainda demonstravam concepções e práticas equivocadas ao lidar com o processo de alfabetização com seus alunos".

\section{METODOLOGIA}

O presente estudo foi desenvolvido a partir de uma revisão bibliográfica de abordagem descritiva, realizada no primeiro semestre de 2018. A delimitação do período para a seleção dos trabalhos foi a publicação compreendida entre 2013 a 2017, sendo autores dos trabalhos, doutores, especialistas, professores formadores do PNAIC. A delimitação de cinco anos aqui escolhida deve-se ao fato de que a formação de professores alfabetizadores se iniciou em 2012 e finalizou em 2015. Nos anos de 2016 e 2017 houve outra formação. A análise dos dados se deu a partir da Análise de Conteúdo (BARDIN, 2010).

Os dados foram coletados a partir das seguintes bases: Repositório da Universidade Federal de Santa Catarina - UFSC, da Coordenação de Aperfeiçoamento de Pessoal de Nível Superior - CAPES, da Scientific Electronic Library Online - SciELO e do Sistema de Información Científica Redalyc Red de Revistas Científicas de América Latina y el CaribeRedalyc. Os descritores utilizados foram os seguintes: PNAIC; PNAIC and leitura; PNAIC and leitor; PNAIC and avaliação; PNAIC and formação; PNAIC and Educação Básica, incluindo-se o operador booleano “and". No tocante aos critérios de inclusão e exclusão, estes foram baseados a partir da leitura dos trabalhos completos encontrados. Incluíram-se trabalhos que versavam em sua íntegra acerca do PNAIC, letramento, formação. Excluíram-se trabalhos repetidos e que não compreendiam o critério de inclusão anteriormente citado. 


\section{RESULTADOS E DISCUSSÃO}

Foram selecionados 14 trabalhos publicados entre 2013 e 2017, sendo 10 artigos, 2 dissertações, seguidos de 1 tese e 1 trabalho de conclusão de curso. Além disso, constatou-se que 13 trabalhos se inscrevem na área da Educação e 1 na área da Linguística, sendo: (3) Revista Ibero-Americana de Estudos, (2) Repositório da Universidade Federal de Santa Catarina, Educação, (1) Repositório da Universidade Estadual Paulista Júlio de Mesquita Filho, (1) Repositório da Universidade Estadual de Ponta Grossa, (1) DELTA, (1) Laplage em Revista, (1) Rev. Bras. Educ, (1) Rev. Bras. Estud. Pedagog, (1) Perspectiva, (1) Educação Por Escrito, (1) Práxis Educativa, conforme descrito no Quadro 1.

Quadro 1. Descrição dos trabalhos encontrados a partir da revisão bibliográfica

\begin{tabular}{|c|c|c|}
\hline ANO & AUTORES & PUBLICAÇÃO \\
\hline 2013 & $\begin{array}{l}\text { BERNARDINO } \\
\text { (TCC) }\end{array}$ & $\begin{array}{l}\text { BERNARDINO, Talita. A compreensão de Alfabetização na Perspectiva } \\
\text { do Letramento: O Programa Nacional de Alfabetização na Idade Certa - } \\
\text { PNAIC/MEC-2012-2013. Trabalho de Conclusão de Curso. 2013, } 41 \text { f, il. } \\
\text { Pedagogia, Centro de Ciências da Educação, Universidade Federal de Santa } \\
\text { Catarina, Florianópolis, 2013. }\end{array}$ \\
\hline 2014 & $\begin{array}{l}\text { SALOMÃO } \\
\text { (Dissertação) }\end{array}$ & $\begin{array}{l}\text { SALOMÃO, Rommy. A formação continuada de professores } \\
\text { alfabetizadores: do Pró-Letramento ao PNAIC. 2014. } 117 \text { f. Dissertação } \\
\text { (Mestrado em Educação) - Universidade Estadual de Ponta Grossa, Ponta } \\
\text { Grossa, 2014. }\end{array}$ \\
\hline 2014 & $\begin{array}{c}\text { SOUZA } \\
\text { (Dissertação) }\end{array}$ & $\begin{array}{l}\text { SOUZA, Elaine Eliane Peres de. A formação continuada do professor } \\
\text { alfabetizador nos cadernos do Pacto Nacional pela Alfabetização na } \\
\text { Idade Certa (PNAIC). 2014, } 358 \text { p. Dissertação (mestrado) - Programa de } \\
\text { Pós-Graduação em Educação, Centro de Ciências da Educação, Universidade } \\
\text { Federal de Santa Catarina, Florianópolis, } 2014 \text {. }\end{array}$ \\
\hline 2015 & $\begin{array}{l}\text { CHAGAS, } \\
\text { DOMINGUES } \\
\text { (Artigo) }\end{array}$ & $\begin{array}{l}\text { CHAGAS, Liane Maria de Moura; DOMINGUES, Chirley. A literatura } \\
\text { infantil na alfabetização: a formação da criança. PERSPECTIVA, } \\
\text { Florianópolis, v. 33, n. 1, 77-95 jan./abr. } 2015 \text {. }\end{array}$ \\
\hline 2015 & $\begin{array}{l}\text { RESENDE } \\
\text { (Tese) }\end{array}$ & $\begin{array}{l}\text { RESENDE, Valéria Aparecida Dias Lacerda de. Análises dos pressupostos } \\
\text { de linguagem nos cadernos de formação em língua portuguesa do Pacto } \\
\text { Nacional pela Alfabetização na Idade Certa - PNAIC. 2015. } 215 \text { f.: il. } \\
\text { color. Tese (doutorado) - Universidade Estadual Paulista Júlio de Mesquita } \\
\text { Filho, Faculdade de Filosofia e Ciências, } 2015 .\end{array}$ \\
\hline 2016 & $\begin{array}{l}\text { ESQUINSANI } \\
\text { (Artigo) }\end{array}$ & $\begin{array}{l}\text { ESQUINSANI, Rosimar Serena Siqueira. O pacto nacional pela alfabetização } \\
\text { na idade certa e a responsabilização (accountability) do professor } \\
\text { alfabetizador. RIAEE - Revista Ibero-Americana de Estudos em } \\
\text { Educação, v. } 11, \text { n. esp. } 4 \text {, p. } 2465-2482,2016 .\end{array}$ \\
\hline 2016 & $\begin{array}{l}\text { GABRIEL, } \\
\text { KOLINSKY, } \\
\text { MORAIS } \\
\text { (Artigo) }\end{array}$ & $\begin{array}{l}\text { GABRIEL, Rosângela; KOLINSKY, Régine; MORAIS, José. O milagre da } \\
\text { leitura: de sinais escritos a imagens imortais. DELTA [online]. vol. 32, n. 4, } \\
\text { pp. 919-951, } 2016 \text {. }\end{array}$ \\
\hline 2016 & $\begin{array}{c}\text { GELOCHA, CORTE } \\
\text { (Artigo) }\end{array}$ & $\begin{array}{l}\text { GELOCHA, Elizandra Aparecida Nascimento; CORTE, Marilene Gabriel } \\
\text { Dalla. Pacto Nacional pela Alfabetização na Idade Certa e a formação de } \\
\text { professores: o que dizem as produções científicas? Educação Por Escrito, } \\
\text { Porto Alegre, v. } 7, \text { n. } 1, \text { p. } 106-123 \text {, jan.-jun. } 2016 \text {. }\end{array}$ \\
\hline 2016 & $\begin{array}{c}\text { GODOY, VIANA } \\
\text { (Artigo) }\end{array}$ & $\begin{array}{l}\text { GODOY, Dalva Maria Alves; VIANA, Fernanda Leopoldina. Conteúdos } \\
\text { linguísticos como subsídio à formação de professores alfabetizadores - a } \\
\text { experiência do Brasil e de Portugal. Rev. Bras. Estud. Pedagog. [online]. } \\
\text { vol. } 97, \text { n. 245, pp. } 82-96,2016 \text {. }\end{array}$ \\
\hline
\end{tabular}


Linguagens - Revista de Letras, Artes e Comunicação - ISSN 1981-9943

Blumenau, v. 13, n. 2, p. 301-319, maio/ago. 2019

DOI: http://dx.doi.org/10.7867/1981-9943.2019v13n2p301-319

\begin{tabular}{|c|c|c|}
\hline 2016 & $\begin{array}{l}\text { MENDONÇA, } \\
\text { KODAMA } \\
\text { (Artigo) }\end{array}$ & $\begin{array}{l}\text { MENDONÇA, Onaide Schwartz; KODAMA, Kátia Maria Roberto de } \\
\text { Oliveira. Alfabetização: por que a criança não a ler e escrever? RIAEE - } \\
\text { Revista Ibero-Americana de Estudos em Educação, v. 11, n. esp. 4, p. } \\
2448-2464,2016 \text {. }\end{array}$ \\
\hline 2016 & $\begin{array}{l}\text { SHIMAZAKI, } \\
\text { MENEGASSE } \\
\quad \text { (Artigo) }\end{array}$ & $\begin{array}{l}\text { SHIMAZAKI, Elsa Midori; MENEGASSI, Renilson José. O formador de } \\
\text { professores de Língua Portuguesa do PNAIC e as alterações em suas práticas } \\
\text { profissionais. Práxis Educativa, Ponta Grossa, v. 11, n. 1, p. 199-213, } \\
\text { jan./abr. 2016. }\end{array}$ \\
\hline 2017 & $\begin{array}{l}\text { ARANDA } \\
\text { (Artigo) }\end{array}$ & $\begin{array}{l}\text { ARANDA, Maria Alice de Miranda. O pacto brasileiro de alfabetização nos } \\
\text { municípios de Dourados-MS e Uberlândia-MG: política educacional e gestão } \\
\text { escolar. Laplage em Revista (Sorocaba), vol. 3, n. 3, p. 164-177, set. - dez. } \\
2017 \text {. }\end{array}$ \\
\hline 2017 & $\begin{array}{l}\text { MELLO, CARDOSO } \\
\text { (Artigo) }\end{array}$ & $\begin{array}{l}\text { MELLO, Ângela Rita Christofolo de; CARDOSO, Cancionila Janzkovski. } \\
\text { Metodologias, recursos e estratégias didáticas para o ciclo da alfabetização no } \\
\text { contexto do PNAIC em Mato Grosso: aspectos conceituais e práticos. RIAEE } \\
\text { - Revista Ibero-Americana de Estudos em Educação, v. 12, n. 1, p. 151- } \\
167,2017 \text {. }\end{array}$ \\
\hline 2017 & $\begin{array}{l}\text { ZANCHETTA } \\
\text { JÚNIOR } \\
\text { (Artigo) }\end{array}$ & $\begin{array}{l}\text { ZANCHETTA JÚNIOR, Juvenal. Práticas de leitura literária e a contribuição } \\
\text { do PNAIC. Rev. Bras. Educ. [online]. vol. 22, n. 68, pp. 147-167, } 2017 .\end{array}$ \\
\hline
\end{tabular}

Fonte: Dados da Pesquisa (2018).

Desses estudos, foi observado que o ano de 2016 teve 6 publicações, seguidas de 2017 (3), 2015 (2), 2014 (2) e 2013 (1). Considera-se esse número expressivo de publicações em 2016, em decorrência do término do curso em 2015.

Gráfico 1. Publicações encontradas acerca do PNAIC entre 2013-2017

Publicações (2013-2017)

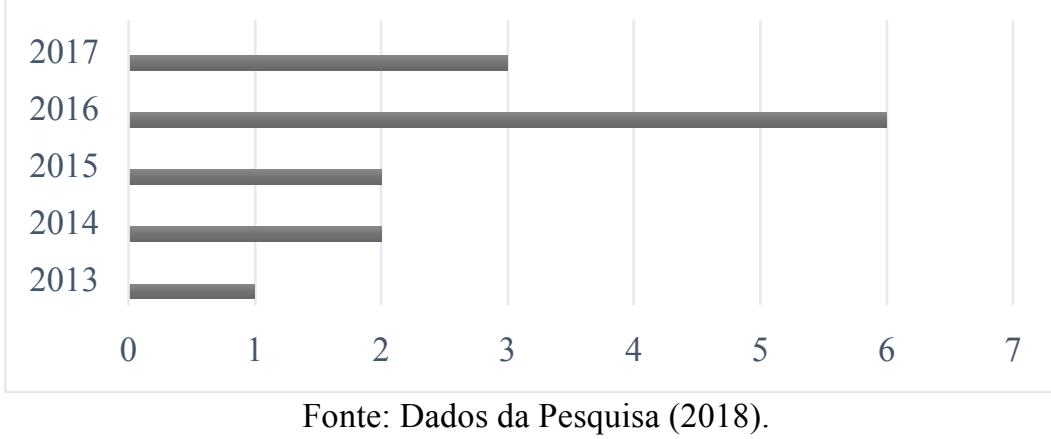

A partir de agora, as discussões serão elencadas sob duas categorias; i) formação continuada do professor alfabetizador; ii) alfabetização, letramento, língua(gem). Essas categorias foram elaboradas a partir da análise das palavras dos resumos dos artigos, conforme se pode observar na imagem abaixo. 


\section{Linguagens - Revista de Letras, Artes e Comunicação - ISSN 1981-9943 \\ Blumenau, v. 13, n. 2, p. 301-319, maio/ago. 2019 \\ DOI: http://dx.doi.org/10.7867/1981-9943.2019v13n2p301-319}

Imagem 1. Nuvem de palavras elaborada a partir do software Word Art

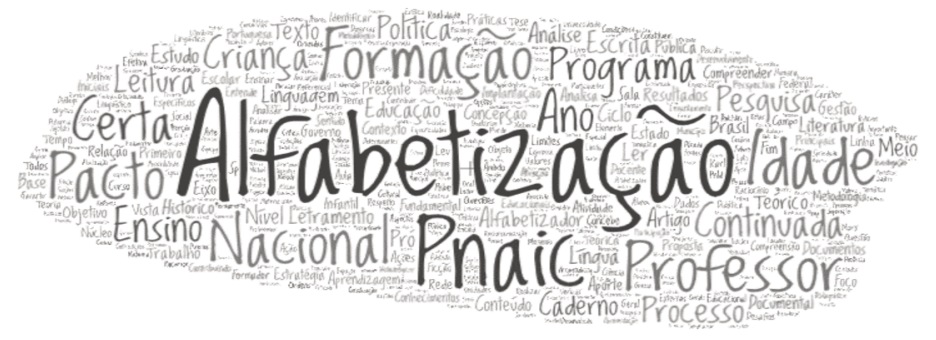

Fonte: Dados da pesquisa (2018).

\subsection{FORMAÇÃO CONTINUADA DO PROFESSOR ALFABETIZADOR}

A pesquisa em nível de mestrado de Salomão (2014) intitulada "A formação continuada de professores alfabetizadores: do Pró-Letramento ao PNAIC" objetivou analisar, por meio de um estudo bibliográfico e documental, acerca do processo de implantação e implementação do PNAIC na rede pública de ensino de Ponta Grossa/PR, visando, assim, contribuir para a superação das dificuldades que os professores alfabetizadores têm encontrado quanto aos processos de ensino e de aprendizagem. A partir das análises realizadas pela autora, atentou-se para dois direcionamentos: um em que a formação continuada mensura a aprendizagem dos estudantes e reforça que a formação inicial não é suficiente e; o outro, que possibilita aos professores em formação continuada uma atualização de seus conhecimentos "fazendo com que a atividade educativa promova a emancipação humana, contribuindo para que o indivíduo tenha participação efetiva na sociedade ao mesmo tempo que transforma sua própria realidade" (SALOMÃO, 2014, p. 9).

Na dissertação de Souza (2014) intitulada “A formação continuada do professor alfabetizador nos cadernos do Pacto Nacional pela Alfabetização na Idade Certa (PNAIC)", a autora realizou uma análise documental a partir do manual Pacto Nacional Pela Alfabetização na Idade Certa: O Brasil do futuro com o começo que ele merece; dos cadernos de Avaliação no Ciclo de Alfabetização; e de Formação do Professor Alfabetizador: caderno de apresentação; de Formação de Professores no Pacto Nacional pela Alfabetização na idade certa e; dos 24 cadernos Alfabetização em Língua Portuguesa do curso de formação para professores alfabetizadores quanto à concepção de formação continuada empregada nesses documentos. Souza identificou duas perspectivas, o construtivismo e o sociointeracionismo abordados nos referidos cadernos de formação do PNAIC. Concluiu que os cadernos visam a 


\section{Linguagens - Revista de Letras, Artes e Comunicação - ISSN 1981-9943 \\ Blumenau, v. 13, n. 2, p. 301-319, maio/ago. 2019 \\ DOI: http://dx.doi.org/10.7867/1981-9943.2019v13n2p301-319}

formar "os professores para garantir os direitos de aprendizagem das crianças", entretanto, estes ainda apresentam

condições incipientes para fornecer ao professor alfabetizador elementos e condições suficientes para ele realizar a atividade de ensino e para ampliar as possibilidades da aprendizagem da criança o que limita o aprofundamento de conhecimentos e o desenvolvimento humano (SOUZA, 2014, p. 11).

O artigo de Esquinsani (2016) "O Pacto Nacional pela Alfabetização na Idade Certa e a Responsabilização (Accountability) do professor alfabetizador" se aproxima da dissertação de Salomão (2014), pois ao mesmo tempo que o PNAIC promove a formação docente para sua atualização do conhecimento coloca-o "como sujeito central da responsabilização sobre os resultados em relação aos processos para os quais foi formado, materializando o accountability como estratégia de política educacional" (ESQUINSANI, 2016, p. 2465). Também fazendo uma análise de documentos que justificam e que configuram o PNAIC, a autora concluiu que recai sobre o professor alfabetizador a meta de alfabetizar as crianças até os oito anos, assim como é dele a responsabilidade de que essas crianças apresentem desempenho satisfatório nas provas/avaliações de larga escala (Avaliação Nacional de Alfabetização - ANA, Prova Brasil).

Gelocha e Corte (2016), indo ao encontro dos trabalhos de Salomão (2014) e Esquinsani (2016), quanto à análise dos limites do PNAIC em relação à formação de professores alfabetizadores, apresentam em seu artigo "Pacto Nacional pela Alfabetização na Idade Certa e a formação de professores: o que dizem as produções científicas?" uma metodologia pautada na análise de documentos sobre a legislação educacional. Os autores se aproximam das pesquisas anteriormente citadas, mas distanciam-se com relação às produções acadêmicas de eventos científicos promovidos pela Associação Nacional de Pós-Graduação e Pesquisa em Educação - ANPEd2 e Associação Nacional de Pós-Graduação e Pesquisa em Educação da Região Sul - ANPEd Sul3. Os resultados da pesquisa apontaram que, ao passo que os artigos científicos têm afirmado que o PNAIC vem promovendo formação continuada ao professor oferecendo a este "a oportunidade de ler, estudar, debater com seus pares, manter-se informado e atualizado em espaços de planejamento coletivo e compartilhado" (GELOCHA; CORTE, 2016, p. 106), por outro lado, os professores ainda não compreendem os conceitos sobre a alfabetização e o letramento ou alfabetizar letrando. Além disso, as autoras consideram que "potencializar a troca de experiências entre professores seja significativo em todos os campos de atuação profissional e educacional”, uma vez que as 


\section{Linguagens - Revista de Letras, Artes e Comunicação - ISSN 1981-9943 \\ Blumenau, v. 13, n. 2, p. 301-319, maio/ago. 2019 \\ DOI: http://dx.doi.org/10.7867/1981-9943.2019v13n2p301-319}

vivências e as experiências pedagógicas dos professores não se findam na sua formação inicial, as quais "precisam ser constantemente reflexionadas e [re]significadas" (GELOCHA; CORTE, 2016, p. 120).

O artigo de Shimazaki e Menegassi (2016), "O formador de professores de Língua Portuguesa do PNAIC e as alterações em suas práticas profissionais", visa a discutir o papel do professor formador do PNAIC a partir da aplicação de um questionário para onze formadores da Universidade Estadual de Maringá/PR. Os resultados sinalizaram para apropriação de conhecimento e mudanças das práticas pedagógicas dos docentes, assim como houve participação desses profissionais com submissão de trabalhos em eventos científicos, participação em projetos de pesquisa, ingresso como docentes em cursos de especialização, ingresso como alunos de cursos de pós-graduação stricto sensu. As autoras concluíram que "O PNAIC, apesar de ter limitações, apresenta-se como possibilidade para a organização do trabalho pedagógico e de estudo e pesquisa para os professores formadores e demais participantes" (SHIMAZAKI; MENEGASSI, 2016, p. 211). Estas ressaltam ainda que "prática sem a teoria torna-se vazia, sem o direcionamento científico necessário" (SHIMAZAKI; MENEGASSI, 2016, p. 211).

$\mathrm{O}$ artigo "Metodologias, recursos e estratégias didáticas para o ciclo da alfabetização no contexto do PNAIC em Mato Grosso: aspectos conceituais e práticos", de Mello e Cardoso (2017), caracterizou-se a partir da socialização das metodologias que os professores alfabetizadores podem utilizar na sala de aula. Entretanto, o que preconizam os cadernos do PNAIC, quanto ao ensino da leitura e da escrita na perspectiva dos letramentos, destoa do modo de ver dos professores em formação, do que tem considerado a Avaliação Nacional de Alfabetização - ANA, ou seja, "avalia a apropriação da leitura e da escrita de forma tradicional e técnica" (MELLO; CARDOSO, 2017, p. 164).

O trabalho de Aranda (2017) "O pacto brasileiro de alfabetização nos municípios de Dourados-MS e Uberlândia-MG: política educacional e gestão escolar" emerge de uma pesquisa realizada a partir de um estágio pós-doutoral. A autora faz uma análise sobre a implementação do PNAIC em dois municípios brasileiros (Uberlândia-MG e Dourados-MS) observando as expectativas, dificuldades e desafios. Pautando-se em um estudo bibliográfico, documental e de campo (questionário aplicado a 50 sujeitos envolvidos em vários segmentos do PNAIC), Aranda (2017) ressalta que este programa, que é recente no país, tem apresentado boas expectativas. Porém, pontua algumas dificuldades quanto a todas as crianças estarem alfabetizadas até o $3^{\circ}$ ano, dentre elas: “[...] a questão da falta de tempo institucionalizado para estudo, para o planejamento das ações encaminhadas nas formações; a preocupação com 


\section{Linguagens - Revista de Letras, Artes e Comunicação - ISSN 1981-9943 \\ Blumenau, v. 13, n. 2, p. 301-319, maio/ago. 2019 \\ DOI: http://dx.doi.org/10.7867/1981-9943.2019v13n2p301-319}

as avaliações em larga escala destinadas às crianças, que além da Provinha Brasil, agora também [realizam] a Avaliação Nacional de Alfabetização (ANA)" (ARANDA, 2017, p. 171).

O texto de Zanchetta Júnior (2017), "Práticas de leitura literária e a contribuição do PNAIC", direciona suas discussões em torno da abordagem teórico-metodológica acerca da leitura de textos literários no PNAIC. O autor aponta em seus resultados que há uma leitura que se caracteriza como "predominantemente escolarizada", a qual "se distancia da estética peculiar aos textos, para compreendê-los com base em valores externos, mas prestigiados socialmente" (ZANCHETTA JÚNIOR, 2017, p. 147). A discussão revela que, embora o PNAIC discorra acerca da formação de professores, pouco enfatiza a formação de professores para a leitura literária em sala. Assim, sem a formação do educador, pouco se compreende acerca da formação do estudante-leitor literário em sala de aula.

Os estudos aqui apresentados apontam para uma prática pedagógica do ensino de leitura direcionada para uma ação escolarizada, distanciando-se dos usos da linguagem em textos autênticos, textos esses que fazem parte do cotidiano do estudante-leitor para além da escola (ZANCHETTA JÚNIOR, 2017). Ou seja, este sujeito caminha/circula por outras esferas da atividade humana, o qual é afetado por elas e também as afeta e se constitui, portanto, por outras leituras em outros tempos e espaços.

\subsection{ALFABETIZAÇÃO, LETRAMENTO, LÍNGUA(GEM)}

O Trabalho de Conclusão de Curso de Bernardino (2013), intitulado "A compreensão de Alfabetização na Perspectiva do Letramento: O Programa Nacional de Alfabetização na Idade Certa - PNAIC/MEC-2012-2013”, se propôs a compreender os conceitos dos processos de alfabetização na perspectiva do letramento a partir de uma análise documental por meio dos Parâmetros Curriculares Nacionais - PCN (BRASIL, 1997), PRÓ-LETRAMENTO (BRASIL, 2008) e PNAIC (BRASIL, 2012b). A autora verificou, com relação aos documentos e programas, que não há uma periodicidade de publicações dos documentos oficiais. Além disso, evidenciou que apesar de haver discussões na teoria sobre mudanças de paradigmas, no caso dos PCN, ainda se observa um ensino tradicional. O PRÓLETRAMENTO e o PNAIC apresentam propostas de ensino direcionadas para o alfabetizar letrando. Pontualmente no PNAIC, se determina a idade certa para que crianças já estejam alfabetizadas - até o $3^{\circ}$ ano do Ensino Fundamental. O autor considera que "com exceção do PNAIC que ainda está em curso, os outros programas ainda deixaram lacunas na formação 


\section{Linguagens - Revista de Letras, Artes e Comunicação - ISSN 1981-9943 \\ Blumenau, v. 13, n. 2, p. 301-319, maio/ago. 2019 \\ DOI: http://dx.doi.org/10.7867/1981-9943.2019v13n2p301-319}

dos professores, que ainda demonstravam concepções e práticas equivocadas ao lidar com o processo de alfabetização com seus alunos" (BERNARDINO, 2013, p. 37).

A tese de doutorado de Resende (2015), intitulada "Análises dos pressupostos de linguagem nos cadernos de formação em língua portuguesa do Pacto Nacional pela Alfabetização na Idade Certa - PNAIC", objetiva analisar os pressupostos de linguagem, explícitos ou não, nos Cadernos de Formação em Língua Portuguesa dos Anos 1, 2 e 3 das Unidades 1 e 3 do PNAIC. O estudo documental de cunho qualitativo fundamenta-se nos pressupostos teórico-epistemológicos de Bakhtin. Resende apresenta como resultados que, nos Cadernos do PNAIC, há uma concepção de língua(gem) pautada nos pressupostos de Ferdinand Saussure, desconsiderando as diversas vozes que ecoam no momento da interação em sala de aula (do estudante, do professor, da família, da comunidade, da história). Assim, a formação de professores não contempla uma formação realmente efetiva, uma vez que pode haver a "ofuscação" da concepção de língua(gem) que ancora o curso. Também menciona que a proposta que ecoa desse material é baseada na ideia de que a escrita alfabética é dada a partir da ênfase na consciência fonológica, portanto, considera de forma velada o processo dialógico e dinâmico da língua em uso e acaba não contemplando efetivamente a fala da criança no processo de apropriação da linguagem escrita. A escrita se constitui nessa pesquisa “como representação da linguagem e não a escrita com uma linguagem” (RESENDE, 2015, p.

8). Segundo a autora:

Acredito ainda que este estudo, na perspectiva discursiva, suscitará outras vozes para o diálogo, para a reflexão, para outros olhares relacionados às atividades de alfabetizar toda criança brasileira, constituindo crianças leitoras e autoras dos seus enunciados orais e escritos, constituídos de sentido e significação forjados no coletivo, na corrente dos acontecimentos sociais, nos quais estão inseridas e se constituindo como sujeitos de linguagem (RESENDE, 2015, p. 159).

$\mathrm{O}$ artigo "Conteúdos linguísticos como subsídio à formação de professores alfabetizadores - a experiência do Brasil e de Portugal", escrito por Godoy e Viana (2016), teve por objetivo identificar os conteúdos linguísticos relacionados ao ensino da leitura a partir do PNAIC (no Brasil) e no PNEP (em Portugal). A análise documental evidenciou que há aproximações entre os dois programas quanto "à organização e às estratégias metodológicas" e diferenças no que se refere à "atualidade dos conteúdos oferecidos aos professores alfabetizadores, assim como o tempo de formação aplicado a este conteúdo" (GODOY; VIANA, 2016, p. 82). As autoras concluíram que, no Brasil, os cadernos de estudos do PNAIC pautam-se na teoria da psicogênese e não apresentam um aprofundamento 


\section{Linguagens - Revista de Letras, Artes e Comunicação - ISSN 1981-9943 \\ Blumenau, v. 13, n. 2, p. 301-319, maio/ago. 2019 \\ DOI: http://dx.doi.org/10.7867/1981-9943.2019v13n2p301-319}

e uma referência quanto às teorias cognitivistas mais relevantes voltadas à leitura, tampouco à neurociência, ressaltando que há "especificidade do ensino sistemático das correspondências grafema-fonema para facilitar a aprendizagem alfabética, em conjunto com a estimulação da consciência fonêmica", ao contrário do que ocorre no PNEP em Portugal (GODOY; VIANA, 2016, p. 93).

Mendonça e Kodama (2016), no trabalho "Alfabetização: por que a criança não aprende a ler e escrever?", se propuseram a investigar, à luz da Linguística, quanto às possíveis mudanças no processo de alfabetização a partir do PNAIC. Os resultados de um Projeto de Extensão desenvolvido em uma escola pertencente à rede municipal de ensino de Presidente Prudente/SP, a qual indicou que $55 \%$ dos alunos chegavam ao final do $5^{\circ}$ ano no nível alfabético, sinalizam para um aporte teórico nos cadernos do PNAIC direcionado para a teoria construtivista. As autoras observaram que não há proposta no que refere à metodologia e estratégias recomendadas para o letramento ou alfabetizar letrando.

Gabriel, Kolinsky e Morais (2016), ao passo que apresentam pontos positivos acerca da concepção de leitura a partir do letramento, criticam a ausência de uma abordagem neurobiológica para a compreensão de leitura e do seu processo no artigo "O milagre da leitura: de sinais escritos a imagens imortais". Os autores reforçam que é preciso "uma abordagem atenta às especificidades do processo de alfabetização" (GABRIEL; KOLINSKY; MORAIS, 2016, p. 945), assim como a abordagem pautada nos letramentos não estaria "dando conta" de incluir ou atender a todos, devido à falta de compreensão das especificidades na leitura que os estudantes apresentam. Por fim, os autores ressaltam:

É importante notar que o Manual do PNAIC não oferece uma definição do termo 'alfabetização' ou do processo pelo qual passa a criança a fim de chegar à situação de 'estar alfabetizada'. Parece bastante óbvio que alguma coisa acontece entre o estado 1 (não estar alfabetizado) e o estado 2 (estar alfabetizado) (GABRIEL; KOLINSKY; MORAIS, 2016, p. 939).

No que diz respeito à alfabetização e seu processo compreendido pelo PNAIC, é possível depreender visões epistemológicas-teóricas-metodológicas diferentes, uma vez que há estudos que vêm apontando para uma prática de ensino da leitura realizada a partir de obras literárias em consonância com os escritos nos cadernos de formação (CHAGAS; DOMINGUES, 2015). Por outro lado, há pesquisas que têm reforçado o discurso que o letramento "não daria conta" de atender a todos os estudantes em fase de alfabetização em virtude da ausência de um trabalho ancorado em uma abordagem neurobiológica (GABRIEL; KOLINSKY; MORAIS, 2016). Assim, as avaliações nacionais para aferirem os índices de 


\section{Linguagens - Revista de Letras, Artes e Comunicação - ISSN 1981-9943 \\ Blumenau, v. 13, n. 2, p. 301-319, maio/ago. 2019 \\ DOI: http://dx.doi.org/10.7867/1981-9943.2019v13n2p301-319}

crianças alfabetizadas até o $3^{\circ}$ ano do Ensino Fundamental têm gerado críticas, pois acabam divergindo do que apregoam os cadernos do PNAIC na perspectiva dos letramentos (MELLO; CARDOSO, 2017).

\section{CONSIDERAÇÕES FINAIS}

O presente trabalhou buscou analisar as produções acadêmicas sobre o Pacto Nacional pela Alfabetização na Idade Certa - PNAIC, a partir de uma revisão bibliográfica que compreendeu entre o período de 2013 a 2017.

No que concerne à concepção de formação continuada do professor alfabetizador do PNAIC, os estudos destacam dois aspectos: um positivo quando trata da formação continuada em serviço como apropriação e atualização de conhecimentos, de interação, de diálogo entre teoria e a prática docente, portanto, de um trabalho coletivo visando garantir os direitos de aprendizagem do estudante (SALOMÃO, 2014; SOUZA, 2014; GELOCHA; CORTE, 2016) e; um negativo que tem delegado responsabilidade ao professor alfabetizador quanto ao "sucesso" ou "fracasso" do estudante no processo de ensino e aprendizagem da alfabetização, principalmente a partir das avaliações de larga escala, o que implica também a não compreensão das concepções sobre alfabetização e letramento inscritos nos cadernos do PNAIC por parte dos professores alfabetizadores (SALOMÃO, 2014; SOUZA, 2014; ESQUINSANI, 2016; GELOCHA; CORTE, 2016; SHIMAZAKI; MENEGASSI, 2016; ARANDA, 2017).

No tocante à concepção de alfabetização, letramento, língua(gem), os estudos apontaram para diversas concepções de alfabetização, letramento e linguagem nos cadernos de estudos do PNAIC e na prática docente, ora pautadas no ensino tradicional (BERNARDINO, 2013), ora dando ênfase a consciência fonológica (RESENDE, 2015), ora voltando-se para a teoria da psicogênese (GODOY; VIANA, 2016), ora direcionando para uma teoria construtivista (MENDONÇA; KODAMA, 2016).

Salienta-se que estudos descritivos como o aqui apresentados oferecem dados que podem ser utilizados para estudos comparativos futuros, a partir da observação das mudanças histórico-sociais que ocorrem. Assim, a partir desse estudo, considera-se que há lacunas deixadas por essas pesquisas realizadas em sua maioria na área da Educação, com vistas a reduzir o índice de alfabetismo no país. Considera-se, contudo, que ainda há necessidade de um aprofundamento quanto às concepções de leitura, assim como na caracterização das práticas de alfabetização e no processo de ensino e aprendizagem em sala de aula, pautadas 


\section{Linguagens - Revista de Letras, Artes e Comunicação - ISSN 1981-9943 \\ Blumenau, v. 13, n. 2, p. 301-319, maio/ago. 2019 \\ DOI: http://dx.doi.org/10.7867/1981-9943.2019v13n2p301-319}

em uma fundamentação teórico-metodológica consistente, em função da presença de diferentes compreensões teóricas que são apresentadas, muitas vezes, de modo superficial e, até mesmo, conflitivos entre si nos cadernos do PNAIC.

\section{REFERÊNCIAS}

ALFERES, Marcia Aparecida; MAINARDES, Jefferson. O Pacto Nacional pela Alfabetização na Idade Certa em ação: revisão de literatura. Ensaio: aval. pol. públ. Educ., Rio de Janeiro, v. 27, n. 102, p. 47-68, jan./mar. 2019. Disponível em: https://www.scielo.br/pdf/ensaio/v27n102/1809-4465-ensaio-S010440362018002601262.pdf. Acesso em: 12 maio 2020.

ARANDA, Maria Alice de Miranda. O pacto brasileiro de alfabetização nos municípios de Dourados-MS e Uberlândia-MG: política educacional e gestão escolar. Laplage em Revista (Sorocaba), vol. 3, n. 3, set. - dez. 2017, p. 164-177. Disponível em:

http://www.laplageemrevista.ufscar.br/index.php/lpg/article/view/387/593. Acesso em: 23 abr. 2018.

BARDIN, Laurence. Análise de conteúdo. 4. ed. rev. e atual. Lisboa: Edições 70, 2010.

BERNARDINO, Talita. A compreensão de Alfabetização na Perspectiva do Letramento: O Programa Nacional de Alfabetização na Idade Certa - PNAIC/MEC-2012-2013. Trabalho de Conclusão de Curso. 2013, 41 f, il. Pedagogia, Centro de Ciências da Educação, Universidade Federal de Santa Catarina, Florianópolis, 2013. Disponível em: https://repositorio.ufsc.br/bitstream/handle/123456789/163056/Talita\%20Bernardino.pdf?seq uence=1. Acesso em: 23 abr. 2018.

BRASIL. Parâmetros curriculares nacionais: língua portuguesa. Secretaria de Educação Fundamental. Brasília: MEC/SEF, 1997. Disponível em: http://portal.mec.gov.br/seb/arquivos/pdf/livro02.pdf. Acesso em: 22 maio 2020.

BRASIL. Programa Gestão da Aprendizagem Escolar - GESTAR I. 2004. Disponível em: http://portal.mec.gov.br/index.php?option $=$ com_docman\&view $=$ download\&alias $=446$ apresentacao-geral-gestar-2-2009\&category_slug=documentos-pdf\&Itemid=30192. Acesso em: 07 jul. 2016.

BRASIL. Programa Gestão da Aprendizagem Escolar - GESTAR II. 2006. Disponível em: http://portal.mec.gov.br/index.php?option=com_docman\&view=download\&alias=446apresentacao-geral-gestar-2-2009\&category_slug $=$ documentos-pdf\&Itemid=30192. Acesso em: 07 jul. 2016.

BRASIL. Pró-Letramento: Programa de Formação Continuada de Professores dos Anos/Séries Iniciais do Ensino Fundamental: alfabetização e linguagem. ed. rev. e ampl. incluindo SAEB/Prova Brasil matriz de referência/ Secretaria de Educação Básica. Brasília: Ministério da Educação, Secretaria de Educação Básica, 2008. 


\section{Linguagens - Revista de Letras, Artes e Comunicação - ISSN 1981-9943 \\ Blumenau, v. 13, n. 2, p. 301-319, maio/ago. 2019 \\ DOI: http://dx.doi.org/10.7867/1981-9943.2019v13n2p301-319}

BRASIL. Portaria No 867, de 4 de julho de 2012. Institui o Pacto Nacional pela Alfabetização na Idade Certa e as ações do Pacto e define suas diretrizes gerais. Diário Oficial da União, 5 jul. 2012a.

BRASIL. PNAIC. Avaliação no ciclo de alfabetização: reflexões e sugestões, 2012b. Disponível em: http://www.serdigital.com.br/gerenciador/clientes/ceel/material/107.pdf. Acesso em: 20 ago. 2018.

BRASIL. PNAIC. Alfabetização. 2013. Disponível em: http://pacto.mec.gov.br/o-pacto. Acesso em: 03 set. 2015.

BRASIL. PNAIC. Alfabetização. 2014. Disponível em: http://pacto.mec.gov.br/o-pacto. Acesso em: 07 jul. 2016.

BRASIL. Secretaria de Educação Básica. Diretoria de Apoio à Gestão Educacional. Pacto Nacional pela Alfabetização na Idade Certa. A oralidade, a leitura e a escrita no ciclo de alfabetização. Caderno 05. Ministério da Educação, Secretaria de Educação Básica, Diretoria de Apoio à Gestão Educacional. Brasília: MEC, SEB, 2015. Disponível em:

pacto.mec.gov.br/materiais-listagem/item/.../16_ff646a924421 ea897f27cf6d21e6bb2. Acesso em: 16 ago. 2018.

BRASIL. Base Nacional Comum Curricular. 2017. Disponível em: http://basenacionalcomum.mec.gov.br/images/BNCC_EI_EF_110518_versaofinal_site.pdf. Acesso em: 14 jul. 2020.

CHAGAS, Liane Maria de Moura; DOMINGUES, Chirley. A literatura infantil na alfabetização: a formação da criança. PERSPECTIVA, Florianópolis, v. 33, n. 1, 77-95 jan./abr. 2015. Disponível em: https://periodicos.ufsc.br/index.php/perspectiva/article/view/2175795X.2014v33n1p77/31211. Acesso em: 24 abr. 2018.

ESQUINSANI, Rosimar Serena Siqueira. O pacto nacional pela alfabetização na idade certa e a responsabilização (accountability) do professor alfabetizador. RIAEE - Revista IberoAmericana de Estudos em Educação, v. 11, n. esp. 4, p. 2465-2482, 2016. Disponível em: https://periodicos.fclar.unesp.br/iberoamericana/article/viewFile/9203/6095. Acesso em: 24 abr. 2018.

GABRIEL, Rosângela; KOLINSKY, Régine; MORAIS, José. O milagre da leitura: de sinais escritos a imagens imortais. DELTA [online]. 2016, vol. 32, n. 4, pp. 919-951. Disponível em: http://www.scielo.br/scielo.php?pid=S0102-

44502016000400919\&script=sci_abstract\&tlng=pt. Acesso em: 23 abr. 2018.

GELOCHA, Elizandra Aparecida Nascimento; CORTE, Marilene Gabriel Dalla. Pacto Nacional pela Alfabetização na Idade Certa e a formação de professores: o que dizem as produções científicas? Educação Por Escrito, Porto Alegre, v. 7, n. 1, p. 106-123, jan.-jun. 2016. Disponível em:

http://revistaseletronicas.pucrs.br/ojs/index.php/porescrito/article/view/23455/14622. Acesso em: 24 abr. 2018. 
GERALDI, João Wanderley. Portos de Passagem. 5. ed. São Paulo: Martins Fontes, 2013[1991].

GODOY, Dalva Maria Alves; VIANA, Fernanda Leopoldina. Conteúdos linguísticos como subsídio à formação de professores alfabetizadores - a experiência do Brasil e de Portugal. Rev. Bras. Estud. Pedagog. [online]. 2016, vol. 97, n. 245, pp. 82-96. Disponível em: http://www.scielo.br/scielo.php?pid=S2176-

66812016000100082\&script=sci_abstract\&tlng=pt. Acesso em: 23 abr. 2018.

INAF. Indicador de Alfabetismo Funcional: Resultados Preliminares, 2018. Disponível em: http://acaoeducativa.org.br/wp-content/uploads/2018/08/Inaf2018_Relat\%C3\%B3rioResultados-Preliminares_v08Ago2018.pdf. Acesso em: 08 set. $20 \overline{1} 8$.

KLEIMAN, Angela. (org.). Os Significados do letramento. Campinas, SP: Mercado de Letras, 1995.

MELLO, Ângela Rita Christofolo de; CARDOSO, Cancionila Janzkovski. Metodologias, recursos e estratégias didáticas para o ciclo da alfabetização no contexto do PNAIC em Mato Grosso: aspectos conceituais e práticos. RIAEE - Revista Ibero-Americana de Estudos em Educação, v. 12, n. 1, p. 151-167, 2017. Disponível em:

https://periodicos.fclar.unesp.br/iberoamericana/article/view/8144/6257. Acesso em: 23 abr. 2018.

MENDONÇA, Onaide Schwartz; KODAMA, Kátia Maria Roberto de Oliveira. Alfabetização: por que a criança não a ler e escrever? RIAEE - Revista Ibero-Americana de Estudos em Educação, v. 11, n. esp. 4, p. 2448-2464, 2016. Disponível em: https://periodicos.fclar.unesp.br/iberoamericana/article/view/9202/6094. Acesso em: 23 abr. 2018.

NASCIMENTO, Daniele Maurina do Nascimento; HERNANDES, Elianeth Dias Kanthack Hernandes; SANTOS, Camila Sílvia dos Santos. Formação de professores leitores: um estudo sobre o PNAIC. In: Anais do XII Congresso Nacional de Educação - EDUCERE, Curitiba: PUCPR, 2015. p. 21761- 21772. Disponível em: https://educere.bruc.com.br/arquivo/pdf2015/20330_9648.pdf. Acesso em: 12 maio 2020.

RESENDE, Valéria Aparecida Dias Lacerda de. Análises dos pressupostos de linguagem nos cadernos de formação em língua portuguesa do Pacto Nacional pela Alfabetização na Idade Certa - PNAIC. 2015. 215 f.: il. color. Tese (doutorado) - Faculdade de Filosofia e Ciências, Universidade Estadual Paulista Júlio de Mesquita Filho, São Paulo, 2015. Disponível em: http://hdl.handle.net/11449/123673. Acesso em: 24 abr. 2018.

ROJO, Roxane Helena Rodrigues. Letramento e capacidades de leitura para a cidadania. 2004. Disponível em:

http://arquivos.info.ufrn.br/arquivos/2013121153a8f1155045828c12733b68e/Letramento_e_c apacidade_de_leitura_pra_cidadania_2004.pdf. Acesso em: 02 nov. 2018.

SALOMÃO, Rommy. A formação continuada de professores alfabetizadores: do PróLetramento ao PNAIC. 2014. 117 f. Dissertação (Mestrado em Educação) - Universidade Estadual de Ponta Grossa, Ponta Grossa, 2014. Disponível em:

http://tede2.uepg.br/jspui/handle/prefix/1376. Acesso em: 23 abr. 2018. 
SHIMAZAKI, Elsa Midori; MENEGASSE, Renilson José. O formador de professores de Língua Portuguesa do PNAIC e as alterações em suas práticas profissionais. Práxis

Educativa, Ponta Grossa, v. 11, n. 1, p. 199-213, jan./abr. 2016 199. Disponível em: http://www.revistas2.uepg.br/index.php/praxiseducativa/article/view/7206/4763. Acesso em: 24 abr. 2018.

SILVA, Ezequiel Theodoro da. Leitura ou "Lei-Dura"? In: ABREU, Marcia. Leituras no Brasil: antologia comemorativa pelo 10. COLE. Campinas: Mercado de Letras, 1995. p. 2327.

SOUZA, Elaine Eliane Peres de. A formação continuada do professor alfabetizador nos cadernos do Pacto Nacional pela Alfabetização na Idade Certa (PNAIC). 2014, 358 p. Dissertação (mestrado) - Programa de Pós-Graduação em Educação, Centro de Ciências da Educação, Universidade Federal de Santa Catarina, Florianópolis, 2014. Disponível em: http://gepoc.paginas.ufsc.br/files/2016/08/SOUSA-Elaine-Disserta\%C3\%A7\%C3\%A3o.pdf. Acesso em: 23 abr. 2018.

UNESCO. Compromisso Todos pela Educação: Todos pela Educação rumo a 2022. São Paulo, 2006.

ZANCHETTA JÚNIOR, Juvenal. Práticas de leitura literária e a contribuição do PNAIC. Rev. Bras. Educ. [online]. 2017, vol. 22, n. 68, pp. 147-167. Disponível em: http://www.scielo.br/scielo.php?pid=S141324782017000100147\&script=sci_abstract\&tlng=pt. Acesso em: 24 abr. 2018.

\section{AGRADECIMENTOS}

Ao Programa de Bolsas Universitárias de Santa Catarina - UNIEDU PÓSGRADUAÇÃO, mantido pelo Programa de Bolsas do Fundo de apoio à Manutenção e ao Desenvolvimento da Educação Superior - FUMDES. 